This is the accepted version of a paper published as Röder A. and Mühlau, P. (2014) "Are they acculturating? Europe's immigrants and gender egalitarianism", Social Forces 92(3), 899-928. https://doi.org/10.1093/sf/sot126

\title{
Are they acculturating? \\ Europe's immigrants and gender egalitarianism
}

Antje Röder and Peter Mühlau

Corresponding author: Antje Röder, Department of Sociology, Trinity College

Dublin, 3 College Green, Dublin 2, Ireland; Email: aroeder@tcd.ie

A substantial share of Europe's population consists of immigrants and the children of immigrants. Using European Social Survey data, this study examines whether the gender egalitarian values of immigrants are shaped by the gender relations in their origin country and whether they adapt their values to the standards of their residence country. The analyses show that immigrants originating from countries with very inegalitarian gender relations support gender equality less than members of mainstream society. However, immigrants adapt their gender ideology to the standards of their residence country, and the origin context loses force over time. Both, acculturation within the first generation and acculturation across the generations play a role; but women tend to 'assimilate' within the first generation and more thoroughly than men. 


\section{Introduction}

Gender equality is increasingly promoted in public policy across many countries, and appears to be supported by public opinion on egalitarian gender roles (Brooks and Bolzendahl 2004; Treas and Widmer 2000). Yet there are vast differences across the globe, with attitudes in relation to the role of women being considered as one of the main dividing lines between Western countries and other world regions (Inglehart and Norris 2009). Most immigrants move from countries with less gender egalitarian cultures $^{1}$ to countries with greater equality between the sexes. Furthermore, gender unequal attitudes can have a negative impact on a variety of outcomes such as employment or earnings, and may explain at least some of the disadvantage experienced by immigrant women, who face particular obstacles for example in relation to labour market integration (Rubin et al. 2007).

Despite these important issues, comparatively little research systematically explores the gender role attitudes of migrant men and women in this context. The main questions that arise are whether origin country contexts influence gender role attitudes after migration, and whether this influence persists or diminishes over time and across migrant generations, leading to an adjustment to the prevalent standards of the residence country. The previous literature has shown the more socially conservative values of immigrants and their children (Dagevos, Gijsberts and Van Praag 2003; Ersanilli 2012; Röder and Mühlau, 2012). However, research on these attitudes, and specifically migrants' gender roles, has largely focused on a specific group, or a small number of groups of migrants within the same country, such as for example Turks in Germany (Diehl, Koenig and Ruckdeschel 2009; Güngör and Bornstein 2009; Inglehart and Norris, 2003, 2009;), Moroccans and Turks in the Netherlands (De Valk 2006) or Arabs and Hispanics in the United States (Leaper and Valin 1996; Read 2003; Su, Richardson and Wang 2010). The groups studied tend to come from less gender egalitarian countries, and while they are frequently found to also have less egalitarian attitudes than the native population in the relevant host country, there has been no study to date that systematically investigates the impact of the country of origin on migrants' gender role attitudes. This is done here by comparing the attitudes of migrants from countries that differ relatively little from the host country in terms of gender egalitarianism to those from regions where gender inegalitarian beliefs are much more prevalent.

A related question is whether acculturation occurs largely within the first generation, or mainly between generations. Studies have shown that amongst natives, cohort replacement rather than within cohort change contributes to the shift in average gender role attitudes in many countries (e.g. Bolzendahl and Myers 2004). On the other hand, there is evidence that individuals may experience changes in their attitudes later in life if they are exposed to different beliefs (Cunningham 2008). The within generation change is systematically compared to the between generation change here. Unlike much previous research, this study includes not only first and second generation migrants, but also natives as a reference category, and the children of one native and one immigrant parent. The latter can be expected to be better integrated in the host society (Kalmijn 2010), and may therefore differ quite strongly from those with two foreign born parents. 
Lastly, but perhaps most importantly, this study systematically explores gender differences in acculturation patterns. Male and female experiences after migration differ notably, with men frequently experiencing downward mobility, whereas many women for the first time enter the labour market, which is accompanied by changes in the endowment with social and economic resources and in how they see their position in society (Fernández-Kelly and Garcia 1990). There are diverging claims in relation to the acculturation of male and female migrants. On the one hand, it has been argued that immigrant women and their daughters are more strictly monitored than men and boys (Idema and Phalet 2007). On the other hand, adoption of values may not only be driven by exposure to these ideas, but also influenced by interests (Bolzendahl and Myers 2004). Hence, immigrant women and their daughters would have more reason to adopt egalitarian beliefs than men, as they have more to gain, whereas males may perceive a loss in status as a result. Indeed, empirical evidence does supports the latter argument, in that immigrants women and their daughters are more gender egalitarian (e.g. Dasgupta 1998; Idema and Phalet 2007). However, this gender difference is also pronounced amongst the native population (e.g. Treas and Widmer 2000), and in itself does not necessarily provide sufficient evidence for differential acculturation patterns. By investigating gender differences in relation to the influence of the origin country as well as intra-and inter-generational change, this study contributes to this discussion by systematically exploring the gendered nature of acculturation in this area.

\section{Gender-egalitarianism in post-industrial societies}

A wealth of research has documented that gender egalitarianism is on the rise in modern post-industrial societies, and that the primacy of the breadwinner role is increasingly being challenged.The best researched case appear to be the United States, where support for gender egalitarian attitudes was growing at least since the 1970s (e.g. Bolzendahl and Myers 2004) but may have plateaued or even 're-traditionalised' since the mid-90s (e.g. Lück 2007; Cotter, Hermsen and Vanneman. 2011). European countries are diverse with regard to their gender culture reflecting for example different religious traditions, differences in welfare state regimes or democratic traditions (e.g. Guo and Gilbert 2012; Treas and Widmer 2000). Some, such as the Nordic countries, exceed US levels of support for gender equality, while others, such as Germany and Italy, lag somewhat behind. Also, for European countries, an increase over time in support for gender egalitarianism has been shown and there is not (yet) any evidence for a reversal of the trend (Lück 2007; Scott, Alwin and Braun 1996; Guo and Gilbert 2012). Moreover, there are some signs of a convergence of gender ideologies in Europe due to a 'catch-up' of European countries with had less egalitarian gender cultures (Pampel 2011).

The increasing support for gender-egalitarian values in post-industrial societies has been connected to increasing levels of education and female employment. However, changes in the composition of the population, i.e. the share of people with higher education, of women being employed or of men partnered with working women, appear to play only a minor role in accounting for these changes. For most countries, the main mechanism is cohort replacement, the substitution of older, less genderegalitarian by younger more gender-egalitarian cohorts (Bolzendahl and Myers 2004; Pampel 2011; Scott, Alwin and Braun 1996). Many of the migrants to Europe come from countries with lower economic and human development where less equal gender 
relations prevail. This leads to the question whether origin country contexts continue to have an influence on migrants after their arrival in Europe, as well as their acculturation within and across generations.

\section{Gender ideologies of immigrants and origin country context}

Does the origin country context have a lasting influence on the gender attitudes of immigrants? Studies on gender attitudes have shown that gender attitudes, like many other attitudes, are very malleable in youth and adolescence but are relatively stable in adulthood (e.g. Alwin, Braun and Scott 1992). Research on changing gender attitudes in the US and European countries has emphasised the importance of cohort replacement as mechanism underlying the trend to more egalitarian gender beliefs in these countries. This implies that exposure to gender ideologies and experiences in the 'impressionable years' (Alwin and Krosnick 1991) have a lasting effect on the gender egalitarian beliefs in adulthood. Most immigrants migrate to their destination country as adults. This implies that they have been raised by parents and in families who enacted gender roles and exposed their children to gender ideologies which were shaped by the prevailing gender relations in their country of origin.

(H1) First generation immigrants have less gender egalitarian values than 'natives'. The difference is expected to be larger for immigrants originating from countries where women are less empowered

Currently, evidence for this hypothesis is mainly indirect and confined to the US, where lower female labour market participation and higher fertility rates of immigrant groups from countries with less egalitarian gender roles are prevalent (e.g. Blau et al. 2008). Moreover, labour market participation and fertility pattern of immigrant groups also differ for the subsequent generation, which has been evaluated as evidence for the inter-generational transmission of gender roles (Antecol 2000). Direct studies on the gender roles of immigrants and evidence for acculturation are mostly based on small samples and restricted to one or very few immigrant communities in one residence country. Overall, however, findings seem to indicate that groups from societies with higher levels of gender inequality have more inegalitarian gender role attitudes than natives, as for example Turks in Germany (Inglehart and Norris 2003; Diehl, Koenig and Ruckdeschel 2009). Moreover, a number of studies have described the strategies of immigrant families and communities to maintain the established gender relations in the country of residence (e.g. Dasgupta 1998).

\section{Intergenerational acculturation of gender attitudes}

Assimilation refers to the 'decline of an ethnic distinction and its corollary cultural and social differences' (Alba and Nee 2003). A long tradition of studies, starting with the experience of early $20^{\text {th }}$ century migrants to the United States, has investigated the extent to which this occurs in different dimensions, such as the achievement of social status (Hirschmann and Wong 1981; Neidert and Farley 1985), linguistic shifts (Stevens 1992), residential segregation (Massey and Mullan 1984), fertility levels (Ford 1990) and inter-marriage (Blau, Blum and Schwartz 1982; Gordon 1964; 
Kalmijn 1991). Acculturation as one dimension of assimilation refers to the adoption of cultural patterns of mainstream society, and 'happens virtually automatically and is usually unintentional' (Gans 2007, p. 153). It was primarily expected that immigrants would integrate into the social and economic systems of the host society, and in this process, shed their particular cultural practices (Warner and Srole 1945; Gordon 1964). More recently, however, it has been argued that socio-economic mobility operates independently from assimilation and acculturation (Gans 2007).

Most assimilation theorists assume that acculturation of immigrant groups is achieved by generational succession (e.g. Alba and Nee 2003). The underlying assumption is that cultural traits are fairly stable for adults; children of immigrants, however, are exposed during their impressionable years to the culture of mainstream society via peer socialisation, education and media consumption. This is consistent with findings of research on change of gender attitudes among the mainstream population, which emphasizes the role of cohort replacement as central mechanism driving changing gender attitudes (e.g. Bolzendahl and Myers 2004).

Unlike members of mainstream society, immigrant children partake in two different cultural spheres. They grow up in immigrant families and communities who consider unequal gender roles as part of their ethnic identity and aim to transmit their cultural values to their children. In many cases, this includes active strategies to shelter their children from the exposure to mainstream society by locating their families in ethnically segregated neighbourhoods, selecting educational institutions, limiting the contact of their children with peers from mainstreams society and arranging intraethnic marriages (Portes and Rumbaut 2001). Some empirical studies suggest that these strategies are only partially successful. For example, foreign born Arab women usually have less egalitarian values than Arab women born in the US (Read 2003). Similarly, second generation Turks in Germany have attitudes that lie between those of natives and first generation Turks (Diehl, Koenig and Ruckdeschel 2009). Based on these theoretical arguments and empirical findings we expect that intergenerational acculturation has as a consequence that the gap in gender-egalitarianism between mainstream society and immigrants is reduced for the second generation, and that intergenerational acculturation also reduces the differences among second generation immigrant groups, i.e. that the origin country context loses its influence on outcomes:

(H2) Second generation migrants (a) have a more egalitarian gender ideology than the first generation; (b) the gender relations of the origin country exert less influence on the gender attitudes for second generation immigrants than for first generation immigrants.

According to the reasoning above, parental strategies and structural conditions preventing the social integration of immigrants inhibit the acculturation of the second generation. Examples are Moroccan and Turkish immigrants in the Netherlands. While gender relations are similarly unequal in both origin countries, De Valk (2006) claims that second generation Moroccans have a far more gender egalitarian orientation than second generation Turks, and relates this to differentials in the degree of social integration of the groups. Inter-marriage is commonly seen as strongest cross-cutting tie (Gordon 1964) and Kalmijn (2010) shows for the Netherlands that children of mixed families are more socially integrated than children with both 
parents from an immigrant community. The central causal mechanism for this is the number of contacts the children have with members of mainstream society. For Poles and Turks in Sweden, Goldscheider, Goldscheider and Bernhardt (2011) show that children from mixed parentage develop more gender-egalitarian practices than children from intra-ethnic marriages. Using mixed parentage versus intra-ethnic parentage as an indicator for social integration, we examine whether children from families with one immigrant parent and one parent from mainstream society systematically differ with regard to their gender-role attitudes and the importance of the origin country of the immigrant parent:

(H3) Children with one parent from mainstream society (a) have a more egalitarian gender ideology than children with two immigrants as parents; (b) the gender relations of the origin country of the immigrant parent(s) exert less influence on the gender attitudes for second generation immigrants from mixed families than from families with two immigrants as parents.

\section{Intra-generational acculturation}

In spite of the alleged importance of childhood and adolescence as 'impressionable years' for the formation of gender role beliefs, many studies have documented that such attitudes can change in later stages if circumstances changes, for example an increased exposure to gender egalitarian beliefs triggers changes in value orientation (e.g. Cunningham 2008). Migration requires for many people to establish themselves in a context where attitudes and gender relations of the mainstream society are substantially different from what they are used to in their origin country. Families experience this as challenge to their gender ideology and studies point to intra-familial processes of re-negotiating the established gender roles (Dion and Dion 2001).

Empirical studies indicate that the exposure to the prevalent values and discourses in the host society values may induce some acculturation among the first generation. For example, Latino immigrants gender egalitarianism appears to be correlated with length of stay in the United States (Leaper and Valin 1996). The attitudes of Muslims in Europe seem to be placed roughly half way between host country and origin country attitudes (Inglehart and Norris 2009). Longer residence, and thus greater exposure to host country norms and discourses, is therefore expected to be linked to greater acceptance of gender egalitarian beliefs, and a weaker influence of the origin country context.

(H4) The longer immigrants have stayed in the country of origin the more egalitarian their gender ideology and the less important the origin context is for their gender ideology

\section{Gender differences in acculturation patterns}

Do acculturation patterns differ between male and female immigrants and their sons and daughters? Women tend to be seen as responsible for maintaining the culture of the immigrant group, placing additional moral expectations on them (Billson, 1995), and families appear to be more carefully sheltering daughters from exposure to the 
dominant culture of mainstream society. It has been documented that girls are more strictly monitored than boys (e.g. Idema and Phalet 2007) which from an exposure point of view suggests that female immigrants, at least the second generation, should hold less gender-egalitarian attitudes than male immigrants.

Previous research, however, points in the opposite direction. For example, Dasgupta (1998) finds that the daughters of Indian immigrants hold significantly less inegalitarian gender role attitudes than sons and parents. Güngör and Bornstein (2009) report that girls in Turkish migrant families have less conservative gender role attitudes than boys and adapt more to the host society's beliefs. Adoption of genderegalitarian values appears to be not only driven by 'passive' exposure to these values. Interest-based explanations are considered to be the major alternative to exposurebased explanations of gender-egalitarian beliefs (Bolzendahl and Myers 2004). Individuals are likely to adopt or reject gender-egalitarian attitudes (and seek or avoid exposure to those ideas) if these values are congruent with the individual's interests. For female immigrants, the gender egalitarian values of mainstream societies entail a liberating promise. Girls who grew up in the host society may no longer be willing to accept norms that place them at a disadvantage when they are aware of and surrounded by alternative beliefs. Additionally, stricter expectations toward daughters of immigrants can lead to increased resistance by girls and a rejection of genderinegalitarian beliefs (Dasgupta 1998; Arends-Tóth and Van der Vijver 2009). For the first generation, a similar pattern may occur in that women embrace egalitarianism more rapidly than men, although there is currently less empirical evidence for this. A central mechanism appears to be a challenge to the familial power structure by increased control about economic and social resources by women and a parallel decline of men's extra-familial status (e.g., Pessar 1984; Kibria 1990; Lim 1997). Men in contrast may continue to insist on these norms and perceive their social position as threatened by the changing role of women (Hondagneu-Sotelo 2003). Considering that female immigrants and their daughters have a strong interest to adopt of gender-egalitarian beliefs while male immigrants and their sons have a strong interest in preserving unequal gender relations, the last hypothesis is:

(H5) Immigrant women acculturate more strongly than men within and across generations: immigrant women (a) adapt quicker to the gender culture of the residence country and (b) first and second generation women are less strongly influenced by the origin context than men.

\section{Data}

Data were extracted from Rounds 2 and 4 of the European Social Survey (ESS) collected in 2004 and 2008. These are two rounds for which measures of gender egalitarianism are included. The ESS is particularly useful for a cross-national study because it not only covers a wide range of European countries, but also because it is designed to allow cross-national analyses by ensuring that the questions are understood in the same way by respondents in different countries and languages. It is a high quality data set where the sampling design approximates a simple random sample and has a relatively high response rate 
We use data from 27 out of 33 countries covered by the second and fourth round of the ESS. These include the EU 15 countries and the EFTA states Iceland, Norway and Switzerland. Further, nine new member states (Bulgaria, Czech Republic, Estonia, Hungary, Latvia, Poland, Romania, Slovenia and Slovakia) ${ }^{2}$ are included. We exclude Turkey, Ukraine, Russia, Cyprus, Croatia and Israel from the analysis.

Immigrant groups: In the dataset for this analysis we include natives, defined as individuals whose parents and who themselves were born in a country, first generation immigrants, defined as respondents whose parents and who themselves were born abroad, second generation immigrants, who were born in their country of residence, but whose parents were both born abroad, and second generation immigrants being born in the country of residence with one parents born in the residence country and another being born abroad. We exclude any cases that do not belong into any of the four categories, such as return migrants or second generation immigrants whose parents are born in different countries. These criteria were used to construct the four categories as clearly as possible and exclude any ambiguous cases. Individuals are seen as nested within their country of residence and their 'community'. First and the two 'second generations' immigrants are in separate communities even if the origin is identical.

Dependent variables: As dependent variables two items contained in the ESS are used to measure gender egalitarian attitudes. These items are 'When jobs are scarce, men should have more right to a job than women' and 'A woman should be prepared to cut down on her paid work for the sake of her family'. They were measured on a five point scale from strongly disagree to strongly agree and have been reversed for the analysis so that positive values reflect more gender egalitarian beliefs. Both items are related to one domain of gender egalitarianism, the primacy of the breadwinner role (Davis and Greenstein, 2009). However, the former is more strongly linked to equal rights (Brooks and Bolzendahl 2004) while the latter expresses the idea that women should sacrifice their career when caring roles become salient. The considerably lower disagreement with the second item by natives (and immigrants) (see Appendix 1) and the small differences between native women and men (see results) likely reflect that different variations of the male breadwinner/female carer model (Lewis, 1992) are still firmly institutionalized in European societies.

Independent variables: The most important independent variables in the model are immigrant status, gender, gender relations in the residence country and how much they differ between the residence and the origin country, as well as the length of stay of first generation immigrants in the country of residence (see Appendix 1 for descriptive results).

Immigrant status was assessed according to the country of birth of the respondent and parents' country of birth, and includes natives (reference category), first generation, second generation with two foreign born parents and second generation with one foreign born parent (see above).

Gender is measured by a dummy variable 'female' which takes the value 0 for men and the value 1 for women. 
Gender relations at the country of residence are measured by the Gender Empowerment Measure (GEM). The GEM measures the degree to which men and women equally actively participate in economic and political life and is understood as a macro-level proxy for egalitarian gender relations. This is covered by three dimensions: Female representation in national parliaments as an indicator of political representation, female representation in managerial, professional and semiprofessional positions in the economy and the gap in earned incomes between men and women (UNPD 2009). Compared with alternative measures such as the Gender Development Index (GDI) or the Gender Inequality Index the measure has a lower coverage and may be biased to 'elite-participation', but it has the advantage that it is less confounded with general human development problems (see Klasen 2006) and has a higher prima facie validity than alternative measures.

The GEM has a range between 0 and 1 . We chose 2005 as the reference year. For 80 countries, values for the reference year were available. For further 12 countries the values of adjacent years (ranging from 2000 to 2007) were used. For countries for which these were not available, values were substituted by the average of region $\mathrm{X}$ religion cells. The substitution was based on 13 regions reflecting geographical proximity and similarities in development and political and cultural heritage and on whether the country is predominately Muslim or not.

Distances between origin and residence country (GEM Host-Origin) were measured as the difference between the GEM of the origin country and the GEM of the residence country ${ }^{3}$. The results are also robust with regard to gender equality measure chosen $^{4}$.

Length of stay was measured linearly in years. In the ESS, length of stay is coded into five categories (less than one year, one to 5 years or less, 6 to 10 years and 11 to 20 years and more than 25 years). These have been substituted by the mean value of the bracket range $(.5,3,8,15.5$ years) and 37.5 years for the top bracket, and divided by 10 for ease of presentation. Checks indicated that the assumption of linearity is appropriate for the outcome variables.

Control variables. We controlled the regression for several important variables. Both, age and education have been shown to exert a major influence on the gender ideology (e.g. Cunningham 2008). The coefficients for age capture both life-cycle and the probably more important cohort effects. Age is divided by ten for ease of presentation. A further control variable is religious denomination, which is divided into Christian, Muslim and other denominations (reference category: no religion), as religious individuals, and Muslims in particular, tend to hold less egalitarian attitudes (e.g. Diehl, Koenig and Ruckdeschel 2009). Additionally we control for family status in terms of whether a respondent has children in the household, has a partner, and if so, whether he or she is married to the partner (reference category: single without children) and whether or not a respondent and their partner are employed, which are important predictors of attitudes (e.g. Alwin, Braun and Scott 1992). As these variables can have different effects for men and women, separate coefficients are estimated in all models. We decided not to control for other proxies for the degree of acculturation such as language spoken at home or citizenship as both are strongly correlated with the length of stay and the immigrant generation, and are at least partially a function of time spent in the residence country. 


\section{Modelling}

The data have been modelled as hierarchical linear models (multi-level models) using MLwiN $2.27^{5}$. The specification of the models is motivated by the nesting of the data and the structure of the hypotheses we aim to test in order to evaluate whether the data support the core ideas of our theoretical sketch. The hypotheses require a direct comparison of how variables measured at the level of the surveyed countries affect migrants relative to natives. Further, it is expected that these effects differ for first and second generation migrants and sub-groups thereof. Moreover, earlier research has shown that attitudinal and positional outcomes of migrants do not only depend on the circumstances of the residence and origin countries, but also on how they work together (e.g. Van Tubergen, Maas and Flap 2004). This is among others reflected in the fact that the most important independent variable is measured as distances (differences) between survey countries and countries of origin. Accordingly, data of natives and of first- and second-generation migrants have been analysed in one model with three levels: Individuals at the lowest $(n=82,036$ of which 5,208 are first generation migrants. 1,430 are second generation migrants with both parents being immigrants and 3,810 children of mixed parentage) and countries of residence as the highest level $(n=27)$. In between are units at the second level, the 'communities'. Communities are defined as (Country of residence $\mathrm{X}$ country of origin X immigrant status)-cells. An implication of this modelling strategy is that natives form a separate cluster of 'communities' (for more information on communities see Appendix 2).

As there are no second-level units containing both natives and immigrants, the differences between natives and immigrants are measured at the second-level of communities and not at the level of individuals. We have consequently chosen to separate first and the two types of 'second generation' immigrants from the same country of origin in the same country of residence in different units, because this simplifies the model substantially ${ }^{6}$. In total, there are 1,592 level 2 units. 27 units comprise natives, 775 units comprise first generation immigrant communities, 243 comprise second generation immigrants with both parents from the immigrants community and 547 units comprise second generation immigrant communities with one parent being immigrant. In total, there are immigrants from 161 different countries of origin ${ }^{7}$.

\section{Results}

For both variables measuring gender ideology two models are presented, with coefficients for men and women reported in separate columns. Positive coefficients indicate more gender egalitarian attitudes and vice versa. The first models (1.1 and 2.1) report the gaps between men and women and between 'natives' and immigrant groups adjusted for control variables. The estimates for the control variables are in line with previous studies. The better educated and the younger the respondents are (or the later they were born considering the importance of cohort effects outlined above) the more egalitarian their gender ideology. Women have more gender egalitarian values, although the gender gap is rather small for the item that mothers 
should cut back work for children. Gender and educational differences are more pronounced for the item that men should have priority for jobs. Being married and having children affects women's attitudes in particular, with more traditional attitudes amongst married women and those with children. If a woman is employed, or a man has a female partner who works, this has a positive effect on egalitarianism. Belonging to a religious denomination, and particular being Muslim, has a strong effect on more gender traditional attitudes.

TABLES 1.1 and 1.2 about here

The second models (1.2 and 2.2) add, at the survey country level, the Gender Empowerment Measure (GEM) as predictor, interacted with each generational group, and at the immigrant group level, the difference between the host and the origin country GEM, for each generation separately. The larger the value for this differential, the larger the gap, i.e. the origin country is less gender egalitarian than the host country. For first generation immigrants, the model also contains the variable length of stay in the residence country. The estimates for the GEM show a strong influence of the residence country context on gender ideology. When interacting the residence country GEM with immigrant status, the coefficients show that the host context exerts a similar influence on the gender attitudes of immigrants and natives. However, a significantly weaker relationship between host country context and gender egalitarianism is estimated for male second generation immigrants with both parents from an immigrant community.

Does origin country socialisation matter? According to the socialisation hypothesis (H1), immigrants, and particularly those from countries with low levels of gender empowerment, are expected to have less gender egalitarian attitudes. The estimates for immigrant status in the first models reveal that first generation immigrants are indeed significantly less gender egalitarian than 'natives'. This effect would be substantially larger if not controlling for religious denomination (-.24 and -.17 for 'men should have priority' and -.25 and -.20 for 'women should cut down on work for sake of family'), as immigrants are on average more likely to belong to a religion than natives. These effect sizes could be compared to having one level more of education or being a generation older. The estimates for the effect of the gap in gender empowerment between residence and origin country are included in the second model for all three groups of migrants to give an indication whether the gender ideology of migrants is affected by the origin context. For first generation migrants, the estimates are strongly significant for both outcome variables and both sexes. Immigrants from countries with similar gender empowerment than the residence country have the same gender attitudes as 'natives'. Immigrants from countries where women are considerably less empowered than in the residence country, on the other hand, have attitudes that are substantially less gender-egalitarian. Taken together, the data are fully supportive for the first hypothesis (socialisation hypothesis) in that gender ideologies of first generations immigrants are shaped by the origin country context.

Does acculturation happen across generations? The intergenerational acculturation hypothesis (H2) suggests that (a) the second generation is more gender egalitarian 
than the first, and that (b) the origin country exerts less influence on this group than on the first generation. The gender ideology of second generation immigrants with both parents from the same immigrant group lies between the attitudes of 'natives' and first generation migrants, and is largely not significantly different from natives. Second generation immigrants with only one parent from an immigrant community have, if anything, a more gender egalitarian attitude than 'natives'. Compared to the first generation, attitudes of the second generation are less traditional, although this difference is not significant for women with two foreign born parents.

The intergenerational acculturation hypothesis also leads us to expect that the gap between the residence country and the country of the parents' origin has a weaker effect for second generation immigrants than for first generation immigrants. The result show that the coefficients of the empowerment gap are significantly smaller for both groups of second generation immigrants than for the first generation, and that the coefficients for these groups are very small and not significantly different from zero. The origin context of their parents does not exert a substantial influence on the gender attitudes of second generation migrants even if they are born to 'ethnic' families. The data are thus supportive of the hypothesis that gender ideology is affected by an intergenerational acculturation process.

Does integration matter? The integration hypothesis (H3) holds that (a) children of two immigrant parents have less egalitarian gender values than people who originate from 'mixed' families with one parent from mainstream society and one immigrant parent, and that (b) the influence of the gender relations in the origin countries of the immigrant parents is less important for second generation immigrants from 'mixed' families than for those from families with two immigrant parents. In line with this hypothesis, we find that children from mixed families have a more egalitarian orientation than children from 'ethnic' families. The differences between the coefficients for people born in the residence country to two immigrant parents and for people born to one immigrant and one native parent are significantly different with the exception of men on the variable 'women should cut down on work for sake of family'(see Models 1.1. and 2.1). It is not the case that the origin country context matters less for people from mixed families, but this is largely because the gender relations of their parents' origin country matter so little for people from 'ethnic' families.

Do first generation migrant acculturate their gender attitudes? The intra-generational acculturation hypothesis (H4) suggests that longer residence is associated with more gender egalitarian attitudes, and with a weaker effect of the origin country. Positive slopes for length of stay - with the exception of male migrants for 'women should cut down on work' - show that first generation immigrants have a more egalitarian gender ideology the longer they are in the country of residence (Models 1.2 and 2.2). However, the coefficients are larger for the item 'men should have more right to job' than for 'women should cut down on work'. The coefficients are significantly different from zero for both items as far as women are concerned. For men, only the coefficient on 'men should have more right to job' is in the expected direction and significant. If the product term between length of stay and the empowerment gap between residence and origin country is added, the coefficients are positive as expected, but only significant for women. In general, the findings are consistent with 
the intra-generational acculturation hypothesis $(\mathrm{H} 4)$, but the relationship is stronger for the item 'men should have more right to job' and for women compared to men.

Is there a gender difference in acculturation? The final hypothesis (H5) is that acculturation patterns differ between female and male immigrants, expecting that (a) women acculturate quicker to the gender ideology prevailing in the residence country, and (b) that they are less strongly influenced by the origin country. In line with this expectation, we find that the empowerment gap between the residence and origin country affects the gender ideology of first generation women to a lesser degree than the attitudes of men (this difference is significant only for 'men have priority for jobs'), and that length of stay slopes are steeper for women than for men, although the difference in the latter effects remains below conventional significance levels. The interpretation that this indicates that women are more eager to adapt to the host country context is further substantiated by the significant coefficient for the product term between the empowerment gap and length of stay for women only. The influence of the origin country context is about the same for men and women who recently migrated to the residence country, but it is considerably and significantly weaker for women who migrated a long time ago.

Figure 1 compares the gender egalitarian values of immigrant women and men to native men and women as the reference group. The figure is based on simulations in which we calculated the predicted scores based on the model with the interaction between length and host-origin country differential (full model not presented here). For the immigrant groups, values have been calculated for different constellations of origin and residence countries. For this purpose we have ranked the differences between residence and origin country, and calculated the outcome for the upper limits of the first quartile ('small difference'), the median ('medium difference'), the third quartile ('large difference') and the ninth decile ('very large difference') of distances between origin and residence country.

FIGURE 1 about here

The values for established immigrants have been calculated for migrants who have been in the country of residence for 35 years. The gap between the lines for the immigrants with 5 years of stay and for the immigrants with 35 years of stay can be seen to represent the extent of intra-generational assimilation. The graphs illustrate the striking difference in the acculturation patterns between men and women as well as differences between the two items. Established female migrants respond to the rightsbased priority item in the same way as native women; for these women the gender relations of their origin do not matter anymore. In contrast to the fully assimilated women, the attitudes of established male migrants are still shaped to some degree by their origin context. However, their attitudes are much more similar to the attitudes of natives than to the attitudes of recently arrived males. When compared with 'men having priority', the acculturation process is much slower for the 'women should cut back'- item. Established women, in particular when they come from countries with very unequal gender relations, continue to hold more traditional than native women, 
but intra-generational change accounts for most of the difference between native women and recent arrivals. For men, there is a substantial gap between established migrants and natives and hardly any difference between recent and established migrants. Turning to the second generation, sons and daughters of mixed parentage (not included in Figure 1) are largely undistinguishable from native born men and women without a migration background. Similarly, the origin context does not appear to play a role for second generation immigrants with two foreign born parents.

What is more important, intra-generational or inter-generational acculturation? We firstly calculate the difference between a first generation migrant who has been in the country for five versus 35 years. We then calculate the difference between a migrant who has been in the country for 20 years and a second generation migrant whose parents were both born abroad as a measure for the extent of inter-generational acculturation. Comparing these values (Table 2) gives an indication of the relative importance of intra- versus inter-generational change. The general pattern is that intragenerational acculturation plays a more important role than inter-generational acculturation for women, especially on the item 'men having priority'. For men, the opposite is the case, and the main change appears to occur between rather than within generations.

TABLE 2 about here

\section{Conclusion and discussion}

European countries experience inward migration from countries with less gender egalitarian cultures. In this study, we show that the country of origin matters for the gender-role beliefs of immigrants. Immigrants from countries with inegalitarian gender cultures hold far less gender egalitarian attitudes than natives or immigrants from countries with similar gender cultures than the host countries. However, this study also shows that these differences do not persist. In line with assimilation theory, gender attitudes of immigrants appear to become more similar to the gender attitudes of natives over time. This acculturation process is almost completed within one generational succession: The gender attitudes of second generation immigrants are difficult to distinguish from the attitudes of members of mainstream society. This holds also for children born to immigrants from very gender-inegalitarian cultures and for children born to less well integrated immigrant families.

Although both inter- and intra-generational acculturation play a role in the process, there are clear indications that the first immigrant generation already tends to adopt the gender egalitarian norms of mainstream society: Longer residing migrants are more likely to subscribe to gender egalitarian views than recent arrivals, and the influence of origin country factors diminishes. The relative importance of the first generation's acculturation differs between women and men and between the nature of the items examined (see below). The broad picture, however, is that much of the differences separating recent immigrants and natives are not any longer visible when established immigrants and natives are compared. 
Assimilation becomes even more apparent in the second generation, especially when considering also those with only one foreign born parent. This group is frequently overlooked in research on the second generation, although they represent a numerically stronger group than the offspring of two immigrant parents. It is well established that inter-marriage is one of the strongest markers of integration (Kalmijn 2010), and much similarity is observed here amongst the offspring of such couples and natives. Interestingly, this group is even more gender egalitarian than the children of two native parents, which shows that they are not merely 'in between' second generation migrants with two foreign-born parents and natives. Indeed it is quite possible that those engaged in inter-ethnic relationships already had a more gender egalitarian orientation to begin with, and that this contributes to the more egalitarian attitudes observed amongst their offspring. Additionally, the formation of inter-ethnic relations may facilitate a reflexive disengagement with established gender beliefs and practices of both the immigrant and native community.

While differences between second generation immigrants with two immigrant parents and with only one foreign born parents emphasize the importance of social integration for acculturation outcomes, it is noteworthy that even those whose parents were both born abroad are more similar to the mainstream than the first generation. The data show little evidence that immigrants from very gender-inegalitarian societies successfully shelter themselves and their offspring from the influences of the host culture and reproduce the gender ideologies of their origin countries. Most studies describing or assuming parental strategies to control exposure to their children to egalitarian gender values are about immigrant populations with a substantial gap in gender equality between residence and origin country, such as Mexicans in the US or Turks in Germany. Comparisons between the descendents of European and Mexican immigrants in the US (Su, Richardson and Wang 2010), or between children of Surinamese and Antillean immigrants and children of Turkish and Moroccan immigrants in the Netherlands (Arends-Tóth and Van de Vijver 2009) emphasize the inter-generational transmission of gender attitudes with little evidence for convergence of the gender attitudes of second generation immigrants. The findings of this study cast doubts whether these are more general patterns. If effective sheltering strategies are primarily used in immigrant communities from strongly unequal gender cultures, the origin context should continue to differentiate between the attitudes of second generation immigrants. According to our analyses, the gender relations of the origin countries ceased to exert a systematic influence on the attitudes of second generation immigrants. This implies that the gap between the attitudes of first generation and second generation immigrants is more strongly reduced for immigrants originating from societies with more unequal gender roles. Future research may be able to analyse further to what extent other factors impede acculturation, in particular religion considering the overall less egalitarian attitudes of Muslims in Europe seen in the data here, and their frequently claimed lack of assimilation (Sniderman and Hagendoorn 2007).

The study also highlights differences between men and women, with women adapting more straightforwardly than men. The outcomes amongst men vary to a greater extent, and this is particularly pronounced for established first generation immigrants. While they are still strongly influenced by the origin country context and have substantially different attitudes then native men, established female immigrants have 
largely embraced the comparatively more egalitarian gender attitudes of native women of the residence countries. This difference in acculturation between male and female migrants reflects what has been suggested based on some qualitative and smaller scale quantitative studies of individual migrant groups (e.g. Dasgupta 1998 for Asian Indian migrants in the US; Güngör and Bornstein 2009 for Turks in Germany), but extends this by showing this pattern more systematically, demonstrating the value of incorporating gender as one of the factors that can 'segment' assimilation trajectories (Curran et al. 2006). Theoretically, these differences point to interest- and power-based explanations as women have a particular self-interest in embracing more egalitarian ideas and are frequently empowered by shifts in the control of resources. The status and identity of immigrant men in contrast is supported by inegalitarian gender ideologies, and men may consequently be more reluctant to adopt gender-egalitarian values. This links to previous research that indicates that male migrants frequently react to the status threat of increasing female empowerment by symbolic and coercive means to preserve their dominance in the family (Hondagneu-Sotelo 1994; Pessar 1984).

These gendered acculturation patterns may have important consequences in other areas, such as marital conflict and family formation amongst immigrant groups. Firstly, differences in gender attitudes between partners are linked to greater likelihood of conflict and even violence in partnerships (Bhanot and Senn 2007). It has been suggested that this may be occurring in immigrant families if women adopt gender egalitarian ideas and behaviours more so than their male partner (Min 2001). A second consequence can be the choice of partner within the first but also the second generation. It is not unusual for migrants, in particular males, to marry a partner from their country of origin, rather than a native or another member of the same migrant group already in the host country (e.g. Lievens 1999), and such couples tend to have a more traditional division of labour (see for example Huschek, De Valk and Liefbroer 2011 for Turks in the Netherlands).

The study revealed also that immigrants adopt host-country standards more quickly and more thoroughly for the item that asked whether men should have priority over women when jobs are scarce than for the item that asked whether women should cut back work for the sake of the family (see Table 2). The first item is more strongly related to the public domain of equal rights between the genders and expresses 'rights-based beliefs' (Brooks and Bolzendahl 2004). In contrast, the second item refers more to 'private' family arrangements and is more akin to 'gender essentialism' of the post-feminist discourse with an emphasis on enacting an 'intensive motherhood' role (Cotter, Hermsen and Vanneman 2011). This also reflects the limited gender equality achieved in European societies with the continuing dominance of variations of the male breadwinner model (see Lewis 1992; Guo and Gilbert, 2012). The acculturation differential between these items may point to a lower legitimacy of inegalitarian attitudes interfering with individual rights and a more fragmented discourse with regard to gender-role enactment, or a stronger importance of values pertaining to 'private' family arrangements for the identity of immigrants. This links to previous research of immigrants in the Netherlands, where cultural values based on family and marital values were more stable than gender role values (Arends-Tóth and Van der Vijver 2009). The acculturation differential may also indicate that immigrants experience stronger tensions between egalitarian values and gendered practices across the life-cycle than native couples (Bühlmann, Elcheroth and 
Tettamanti 2010). It would be of interest to determine which aspects of gender egalitarian beliefs immigrants are more likely to adopt than others. Here, only two dependent variables for gender attitudes could be analysed. Other surveys, including large international studies, frequently use more refined measurements; however, none of these currently allow a study of origin effects due to the absence of country of origin data.

Another limitation is that within generation changes were measured by length of stay in this study. Without panel data it is not possible to exclude the possibility that we are observing migrant cohort effects rather than actual change over time. Yet it is not very plausible that the entire length of stay effect that is observed in this study as well as in other studies would be explained by such selection effects, as this would require earlier cohorts from the same country to have been significantly more gender egalitarian in their orientations than more recent cohorts.

Also, the data used here was not a specific immigrant survey. This had the advantage of allowing the inclusion of natives and respondents with one immigrant parent who do not normally feature in surveys of the immigrant population. However, certain groups of migrants may be underrepresented, despite efforts of the ESS to achieve a representative sample. Less well integrated migrants may be less likely to participate in the study, and these are also groups that are more likely to hold and maintain gender-inegalitarian beliefs. The extent of acculturation may therefore be slightly overestimated here, whereas the general pattern and country level effects are unlikely to be affected. 


\section{Endnotes}

${ }^{1}$ By 'gender cultures' we refer to institutionalised gender relations in a society. 'Gender relations' refer to the totality of mechanisms that structure the (inter)action and access to socially valued resources of women and men. Normative expectations regarding the behaviour of women and men (gender roles) are integral part of gender relations and find their reflection in individual or institutionalised attitudes (or synonymous 'beliefs' or 'ideologies'). We assume that gender relations, gender roles and gender beliefs can be ordered on a continuum between unequal or inegalitarian and equal or egalitarian relations, roles or beliefs. Gender inequality manifest itself among others in unequal access to powerful and socially rewarded social positions and includes gender-bias in the allocation of rewards to positions (England, 2010). While gender roles may be primarily perceived as role differentiation (and not as role hierarchy) and gender beliefs may be primarily articulated as gender difference (rather than unequal worth), a specific orientation and responsibility of women toward family carer roles and a corresponding emphasis on men as family providers is a central mechanism to reproduce unequal access to power, resources and rewards in societies with a strong differentiation between private (family) and public sphere and hence an indicator for gender inegalitarian roles and beliefs.

${ }^{2}$ Models are robust to the exclusion of particular countries, as well as the exclusion of all New Member States.

${ }^{3}$ Since the distances reflect the differences between origin and residence countries in 2005 rather than the migration years of the individual immigrants, it is noteworthy we examined how stable the relative values are over time. For the 72 countries, for which values for the first (1995) and the last year (2009) are available, the correlation is .84.

${ }^{4}$ Using the Gender-Development Index or country-average gender-ideology derived from the World Value Survey leads to similar results (XXXX).

${ }^{5}$ Both ordered logistic and linear models were estimated. As findings did not differ substantially, only the linear models are presented here for ease of presentation and interpretation.

${ }^{6} \mathrm{An}$ implication of this way of modelling is that dummies for first and second generation immigrants are variables that vary at the community level and not an individual level attribute. The regression coefficients for these dummy variables represent thus not the average difference between a first-generation or secondgeneration migrant and a native individual within a country but between the average native and the average first- and second-generation migrant community.

${ }^{7}$ Random intercepts have been specified for the higher levels and random slopes for variables that are interacted with higher level predictor variables. 


\section{References}

Alba, Richard. and Victor Nee. 2003. Remaking the American Mainstream: Assimilation and Contemporary Immigration. Harvard University Press.

Alwin, Duane F., Michael Braun and Jackie Scott. 1992. "The separation of work and the family: Attitudes toward women's labour-force participation in Germany, Great Britain, and the United States" European Sociological Review 8(1): 13-37.

Alwin, Duane F. and Jon A. Krosnick, 1991. "Aging, cohorts, and the stability of socio-political attitudes over the life span" American Journal of Sociology 97(1): 169-95.

Antecol, Heather. 2000. "An examination of cross-country differences in the gender gap in labor force participation rates" Labor Economics 7(4): 409-26.

Arends- Tóth, Judit and Fons J.R. van der Vijver.2009. "Cultural differences in family, marital, and gender-role values among immigrants and majority members in the Netherlands" International Journal of Psychology 44(3): 161-69.

Bhanot, Surbhi and Charlene Y. Seen. 2007. "Attitudes towards violence against women in men of South Asian ancestry: Are acculturation and gender role attitudes important factors?" Journal of Family Violence 22(1): 25-31.

Billson, Janet M. 1995. Keepers of the Culture: The Power of Tradition in Women's Lives. Lexington.

Blau, Peter, Terry Blum, and Joseph Schwartz. 1982. "Heterogeneity and intermarriage" American Sociological Review 47(1): 45-62.

Bolzendahl , Catherine and Daniel J. Myers. 2004. "Feminist attitudes and support for gender equality: Opinion change in women and men, 1974-1998" Social Forces 83(2): 759-90.

Brooks, Clem and Catherine Bolzendahl. 2004. "The transformation of US gender role attitudes: cohort replacement, social-structural change, and ideological learning" Social Science Research 33(1): 106-33.

Bühlmann, Felix, Guy Elcheroth and Manuel Tettamanti. 2010. "The division of labour among European couples: The effects of life course and welfare policy on value-practice configurations" European Sociological Review 26(1): 49-66.

Corrigal, Elisabeth A. and Alison M. Konrad. 2007. "Gender role attitudes and careers: A longitudinal study" Sex Roles 56(11/12): 847-55.

Cotter, David, Joan M. Hermsen and Reeve Vanneman. 2011. "The end of the gender revolution? Gender role attitudes from 1977 to 2008" American Journal of Sociology 117(1): 259-89. 
Cunningham, Mick. 2008. "Changing attitudes toward the male breadwinner, female homemaker family model: Influences of women's employment and education over the life course" Social Forces 87(1): 299-323.

Curran, Sara R., Steven Shafer, Katharine M. Donato and Filiz Garip 2006. "Mapping gender and migration in sociological scholarship: Is it segregation or integration" International Migration Review 40(1): 199-223.

Dagevos, J., Gijsberts, M. And Van Praag, C. 2003. Rapportage minderheden 2003. Sociall and Cultureel Planbureau, Netherlands.

Dasgupta, Shamita. 1998. "Gender roles and cultural continuity in the Asian Indian immigrant community in the U.S." Sex Roles 38(11/12): 953-74.

Davis, Shannon N. and Theodore N. Greenstein. 2009. "Gender ideology: components, predictors and consequences” Annual Review of Sociology 35: 87-105.

De Valk, Helga A.G. 2006. Pathways into adulthood. A comparative study on family life transitions among migrant and Dutch youth. Thela Thesis.

Diehl, Claudia, Matthias Koenig and Kerstin Ruckdeschel. 2009. "Religiosity and gender-equality. Comparing natives and Muslim migrants in Germany" Ethnic and Racial Studies 32(2): 278-301.

Dion, Karen K. and Kenneth L. Dion. 2001. "Gender and cultural adaptation in immigrant families" Journal of Social Issues 37(3): 511-21.

England, Paula. 2010. "The Gender Revolution uneven and stalled" Gender and Society 24(2): 149-66.

Ersanilli, Evelyn. 2012. "Model(ling) citizens? Integration policies and value integration of Turkish immigrants and their descendants in Germany, France, and the Netherlands" Jounal of Immigrant \& Refugee Studies 10(3): 338-58.

Fernández-Kelly, Patricia and Ana Garcia. 1990. "Power surrendered, power restored: The politics of home and work among Hispanic women in Southern California and Southern Florida" in Tilly, Louise A. And Patricia Guerin (eds) Women in Politics in America, New York: Russell Sage Foundation: 215-28.

Ford, Kathleen. 1990. "Duration of residence in the United States and the fertility of U.S. immigrants" International Migration Review 24(1): 34-68.

Gans, Herbert J. 2007. "Acculturation, assimilation and mobility" Ethnic and Racial Studies 30(1): 152-64.

Goldscheider, Fran, Calvin Goldscheider and Eva M. Bernhardt. 2011. "Creating egalitarian families among the adult children of Turkish- and Polish-origin immigrants in Sweden" International Migration Review 45 (1): 68-88.

Gordon, Milton. 1964. Assimilation in American Life: The Role of Race, Religion and National Origins. Oxford University Press. 
Güngör, Derya and Marc H. Bornstein. 2009. "Gender, development, values, adaptation, and discrimination in acculturating adolescents: The case of Turk heritage youth born and living in Belgium" Sex Roles 60(7/8): 537-48.

Guo, Jing and Neil Gilbert. 2012. "Public attitudes and gender policy regimes: Coherence and stability in hard times" Journal of Sociology \& Social Welfare 39(2): 93-120.

Hirschmann, Charles and Wong, Morrison. 1981. 'Trends in socioeconomic achievement among immigrants and native-born Asian Americans, 1960-1976', Sociological Quarterly 22(3): 495-514.

Hondagneu-Sotelo, Pierrette. 1994. Gendered transitions: Mexican experiences of immigration. University of California Press.

Huschek, D., De Valk, H.A.G. and Liefbroer, A.C. 2011. "Gender-role behavior of second-generation Turks: The role of partner choice, gender ideology and societal context" Advances in Life Course Research 16(4): 164-77.

Idema, Hanna and Karen Phalet. 2007. "Transmission of gender-role values in Turkish-German migrant families: The role of gender, intergenerational and intercultural relations" Zeitschrift für Familienforschung 19(1): 71-105.

Inglehart, Ronald and Pippa Norris. 2009. "Muslim integration into Western cultures: Between origins and destinations" HKS Faculty Research Working Papers Series RWP09-007. Harvard Kennedy School.

Inglehart, Ronald and Pippa Norris. 2003. Rising Tide - Gender Equality and Cultural Change. Cambridge University Press.

Kalmijn, Matthijs. 2010. "Consequences of racial intermarriage for children's social integration” Sociological Perspectives 53(2): 271-86.

Kalmijn, Matthijs. 1991. "Shifting boundaries: Trends in religious and educational homogamy" American Sociological Review, 56(6): 786-800.

Kibria, Nazli. 1990. "Power, patriarchy, and gender conflict in the Vietnamese immigrant community" Gender and Society 4(1): 9-24.

Klasen, Stephan. 2006. "UNDP's gender-related measures: Some conceptual problems and possible solutions" Journal of Human Development 7(2): 243-74.

Leaper, Campbell and Dena Valin. 1996. "Predictors of Mexican American mothers' and fathers' attitudes toward gender equity" Hispanic Journal of Behavioral Science 18(3): 343-55.

Lewis, Jane. 1992. "Gender and the development of welfare regimes" Journal of European Social Policy 2(3): 159-73.

Lievens, John. 1999. "Family-forming migration from Turkey and Morocco to Belgium: The demand for marriage partners from the countries of origin" International Migration Review 33(3): 717-44. 
Lim, In-Sook. 1997. “Korean immigrant women's challenge to gender inequality at home. The interplay of economic resources, gender, and family" Gender and Society 11(1): 31-51.

Lück, Detlev. 2007. "The impact of gender role attitudes on women's life course" in Hans-Peter Blossfeld and Heather Hofmeister, editors. Globalization, Uncertainty and Women's Careers. Edward Elgar: 405-43.

Massey, Douglas S. and Brendan P. Mullan. 1984. "Processes of Hispanic and Black spatial assimilation” American Journal of Sociology 89(4): 836-73.

Min, Pyong G. 2001. 'Changes in Korean immigrants' gender role and social status, and their marital conflicts" Sociological Forum 16(2): 301-20.

Neidert, Lisa and Farley, Reynolds. 1985. "Assimilation in the United States: An analysis of ethnic and generation differences in status and achievement" American Sociological Review 50(6): 840-50.

Pampel, Fred. 2011. "Cohort Changes in the socio-demographic determinants of gender egalitarianism" Social Forces 89(3): 961-82.

Pessar, Patricia R. 1984. "The linkage between the household and workplace in the experience of Dominican women in the U.S" International Migration Review 18(4): 1188-212.

Portes, Alejandro and Rubén G. Rumbaut. 2001. Legacies: The Story of the Immigrant Second Generation. University of California Press.

Read, Jen'nan. 2003. "The sources of gender role attitudes among Christian and Muslim Arab-American women" Sociology of Religion 64(2): 207-22.

Röder, Antje And Mühlau, Peter. 2012. "What explains immigrants' high levels of trust in host country institutions?" Journal of Ethnic and Migration Studies 38(5): 777-92.

Rubin, Jennifer, Michael S. Rendall, Lila Rabinovich, Flavia Tsang, Constantijn van Oranje-Nassau, and Barbara Janta. 2008. Migrant women in the European labour force: Current situation and future prospects, European Commission/ RAND Europe.

Scott, Jackie, Duane F. Alwin, D. F. and Michael Braun. 1996."Generations and changing sex-role attitudes: Britain in a cross-national perspective". Sociology 30(3):427-45.

Sniderman, Paul M. And Hagendoorn, L. 2009. When Ways of Life Collide. Princeton University Press.

Stevens, Gillian. 1992. "The social and demographic context of language use in the United States" American Sociological Review 57(2): 171-228. 
Su, Dejun, Chad Richardson and Guang-zhen Wang. 2010. "Assessing cultural assimilation of Mexican Americans: How rapidly do their gender-role attitudes converge to the U.S. mainstream?” Social Science Quarterly, 91(3): 762-76.

Treas, Judith and Eric D. Widmer. 2000. "Married women's employment over the life course: Attitudes in cross-national perspective" Social Forces 78(4): 1409-36.

UNPD. 2009. Human Development Report 2009: Overcoming barriers: Human mobility and development. UNPD.

Van Tubergen, Frank, Ineke Maas and Henk Flap. 2004. "The economic incorporation of immigrants in 18 Western societies: Origin, destination, and community effects" American Sociological Review 69(5): 701-24.

Warner, Lloyd W. and Leo Srole. 1945. The Social Systems of American Ethnic Groups. New Haven: Yale University Press. 
Table 1.1: Multi-Level Linear Regression: Disagreement with 'Men having priority for jobs'

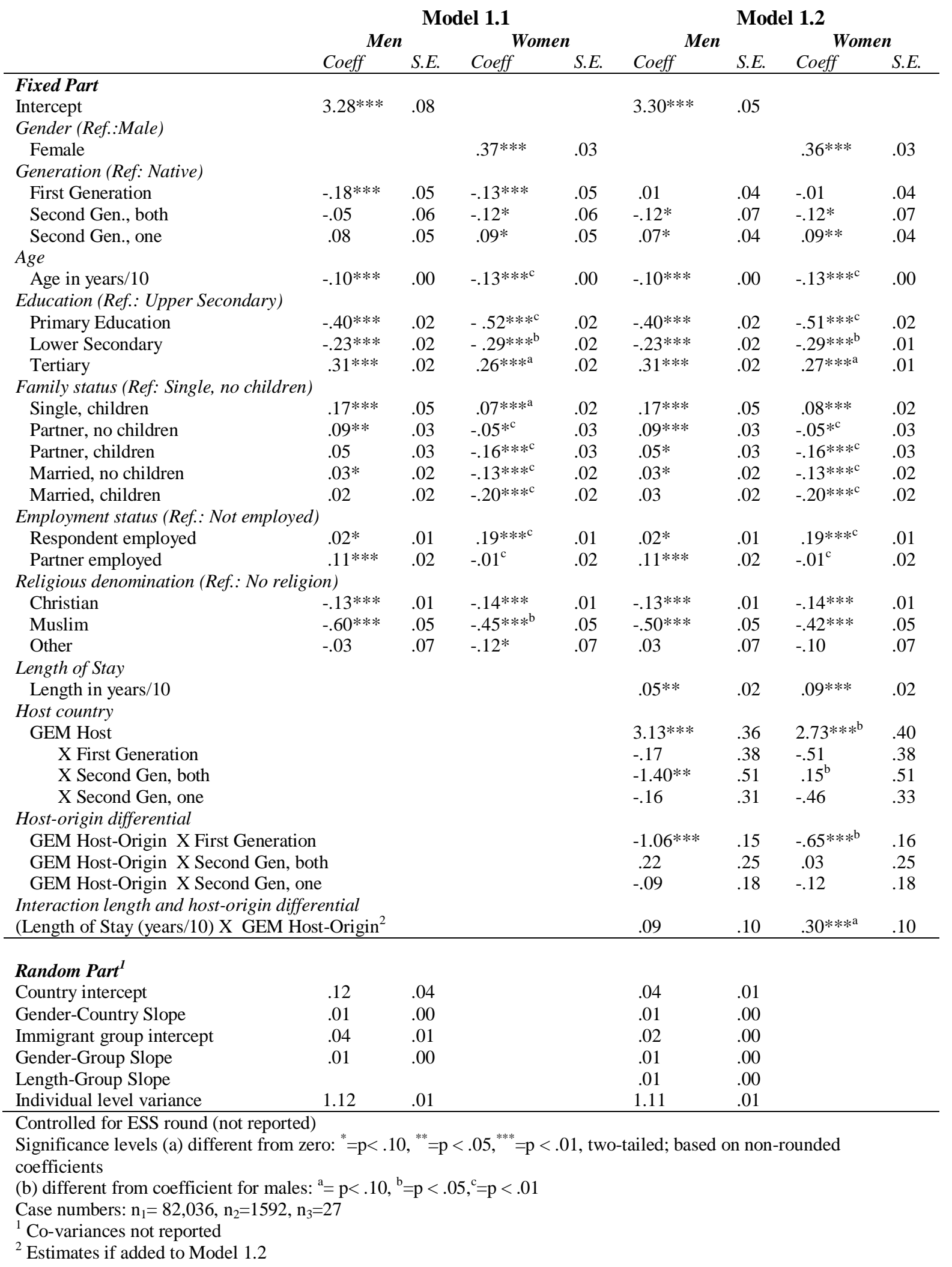


Table 1.2: Multi-Level Linear Regression: Disagreement with 'Women should be prepared to cut back paid work'

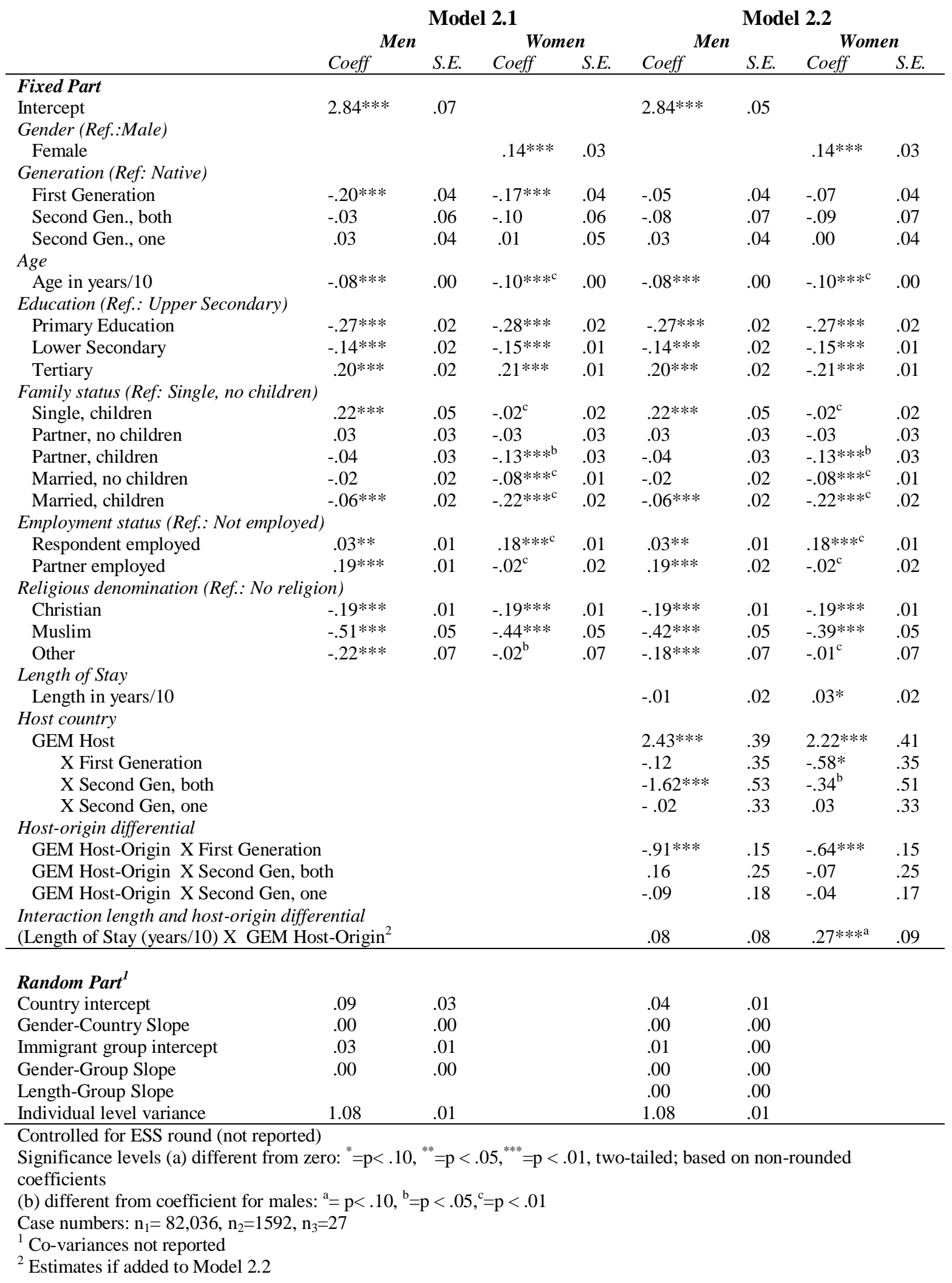


Table 2: Extent of intra- and inter-generational acculturation for women and men from countries with very large difference in GEM

\begin{tabular}{llll}
\hline & & Priority & Cutting back \\
\hline Women & Intra-generational & .52 & .33 \\
& Inter-generational & .23 & .26 \\
\hline Men & Intra-generational & .22 & .04 \\
& Inter-generational & .47 & .44 \\
\hline
\end{tabular}


Appendix 1: Means and percentages of dependent/independent variables by sub-sample

\begin{tabular}{|c|c|c|c|c|}
\hline & Natives & $\begin{array}{l}\text { First- } \\
\text { Generation }\end{array}$ & $\begin{array}{l}\text { Second } \\
\text { generation, both } \\
\text { parents foreign } \\
\text { born }\end{array}$ & $\begin{array}{l}\text { Second } \\
\text { generation, one } \\
\text { parent } \\
\text { foreign born }\end{array}$ \\
\hline \multicolumn{5}{|l|}{ Gender role attitudes } \\
\hline 'Men having priority' & 3.53 & 3.39 & 3.38 & 3.71 \\
\hline 'Women cutting back work' & 2.90 & 2.62 & 2.76 & 2.88 \\
\hline \multicolumn{5}{|l|}{ Gender } \\
\hline$\%$ Female & 53.8 & 54.2 & 52.4 & 53.7 \\
\hline \multicolumn{5}{|l|}{ Age } \\
\hline Age in years & 47.8 & 46.5 & 42.2 & 43.7 \\
\hline \multicolumn{5}{|l|}{ Education } \\
\hline$\%$ Primary Education & 16.8 & 16.4 & 15.9 & 9.4 \\
\hline$\%$ Lower Secondary & 21.0 & 19.9 & 21.5 & 20.4 \\
\hline$\%$ Upper Secondary & 41.8 & 38.5 & 44.0 & 46.0 \\
\hline$\%$ Tertiary & 20.4 & 25.2 & 18.6 & 24.2 \\
\hline \multicolumn{5}{|l|}{ Family status } \\
\hline$\%$ Single, no children & 36.5 & 32.7 & 44.8 & 39.1 \\
\hline$\%$ Single, children & 3.1 & 3.8 & 4.3 & 5.0 \\
\hline$\%$ Partner, no children & 5.0 & 6.2 & 6.4 & 6.9 \\
\hline$\%$ Partner, children & 3.2 & 3.3 & 4.3 & 5.4 \\
\hline$\%$ Married, no children & 32.0 & 26.7 & 23.8 & 24.3 \\
\hline$\%$ Married, children & 20.2 & 27.4 & 16.6 & 19.4 \\
\hline \multicolumn{5}{|l|}{ Employment status } \\
\hline$\%$ Respondent employed & 49.9 & 52.4 & 48.0 & 51.2 \\
\hline$\%$ Partner employed ${ }^{1}$ & 52.1 & 53.2 & 49.1 & 57.3 \\
\hline \multicolumn{5}{|l|}{ Religious denomination } \\
\hline$\%$ No religion & 39.7 & 34.4 & 38.7 & 52.9 \\
\hline$\%$ Christian & 59.3 & 51.1 & 47.0 & 45.6 \\
\hline$\%$ Muslim & .6 & 11.3 & 12.6 & .7 \\
\hline$\%$ Other & .4 & 3.2 & 1.7 & .7 \\
\hline \multicolumn{5}{|l|}{ Length of Stay } \\
\hline Length in years & $\mathrm{n} / \mathrm{a}$ & 23.3 & $\mathrm{n} / \mathrm{a}$ & $\mathrm{n} / \mathrm{a}$ \\
\hline \multicolumn{5}{|l|}{ Host country } \\
\hline GEM Host & .73 & .75 & .72 & .74 \\
\hline \multicolumn{5}{|l|}{ Host-origin differential } \\
\hline GEM Host-Origin & $\mathrm{n} / \mathrm{a}$ & .17 & .18 & .08 \\
\hline $\mathrm{N}$ & 71588 & 5208 & 1430 & 3810 \\
\hline
\end{tabular}


Appendix 2: Immigrant sample by country

\begin{tabular}{|c|c|c|c|c|c|c|c|c|c|c|c|c|c|c|}
\hline & $\mathbf{N}^{1}$ & $\mathrm{OC}^{2}$ & $\mathrm{IC}^{3}$ & GD $^{4}$ & Top & $\mathbf{E U}$ & rigin & & & Top- & Non- & J Oriq & & \\
\hline Austria & 307 & 41 & 72 & .187 & $\mathrm{DE}$ & $\mathrm{CZ}$ & $\mathrm{HU}$ & IT & RO & TR & $\mathrm{BA}$ & RR & HR & EG \\
\hline Belgium & 570 & 50 & 85 & .296 & FR & IT & NL & PL & $\mathrm{DE}$ & MA & TR & $\mathrm{CG}$ & RU & $\mathrm{DZ}$ \\
\hline Bulgaria & 54 & 13 & 22 & .052 & GR & RO & $\mathrm{CZ}$ & GB & $\mathrm{HU}$ & RU & MK & TR & UA & BY \\
\hline Switzerland & 1157 & 84 & 140 & .086 & $\overline{\mathrm{DE}}$ & IT & FR & $\mathrm{AT}$ & ES & TR & HR & $\mathrm{BA}$ & RR & US \\
\hline Czech Republic & 339 & 18 & 35 & .021 & SK & PL & AT & $\mathrm{DE}$ & $\mathrm{HU}$ & RU & UA & $\mathrm{AL}$ & $\mathrm{CU}$ & MD \\
\hline Germany & 747 & 69 & 113 & .248 & PL & $\mathrm{CZ}$ & AT & IT & RO & TR & RU & $\mathrm{KZ}$ & US & RR \\
\hline Denmark & 251 & 56 & 85 & .278 & $\mathrm{DE}$ & $\mathrm{NO}$ & SE & PL & GB & TR & LK & US & MA & $\mathrm{BA}$ \\
\hline Estonia & 1057 & 21 & 35 & .081 & LV & FI & LT & $\mathrm{DE}$ & FR & RU & UA & BY & $\mathrm{AZ}$ & $\mathrm{KZ}$ \\
\hline Spain & 356 & 55 & 75 & .223 & RO & PT & FR & GB & IT & MA & $\mathrm{EC}$ & AR & $\mathrm{CO}$ & $\mathrm{BO}$ \\
\hline Finland & 79 & 23 & 28 & .293 & SE & $\mathrm{EE}$ & $\mathrm{DE}$ & FR & $\mathrm{HU}$ & RU & US & $\mathrm{TH}$ & $\mathrm{CL}$ & $\mathrm{CN}$ \\
\hline France & 623 & 65 & 102 & .147 & IT & ES & PT & $\mathrm{DE}$ & PL & $\mathrm{DZ}$ & MA & $\mathrm{TN}$ & $\mathrm{SN}$ & $\mathrm{CG}$ \\
\hline United Kingdom & 599 & 86 & 143 & .218 & $\mathrm{IE}$ & IT & PL & $\mathrm{DE}$ & ES & IN & PK & JM & $\mathrm{NG}$ & US \\
\hline Greece & 498 & 37 & 58 & .094 & $\mathrm{BG}$ & RO & $\mathrm{CY}$ & GB & PL & TR & $\mathrm{AL}$ & RU & GE & EG \\
\hline Hungary & 140 & 19 & 31 & -.059 & RO & SK & $\mathrm{DE}$ & AT & $\mathrm{PL}$ & US & RR & RU & HR & UA \\
\hline Ireland & 124 & 22 & 26 & .055 & GB & $\overline{\mathrm{DE}}$ & ES & NL & PL & US & $\mathrm{CA}$ & $\mathrm{NG}$ & AT & LK \\
\hline Iceland & 13 & 9 & 10 & .180 & $\mathrm{DE}$ & DK & FI & GB & IT & IN & RU & $\mathrm{TH}$ & & \\
\hline Italy & 22 & 17 & 18 & .099 & FR & BG & $\mathrm{CH}$ & $\mathrm{CZ}$ & $\mathrm{DE}$ & US & AR & BA & EG & $\mathrm{BO}$ \\
\hline Luxembourg & 724 & 46 & 70 & .206 & PT & FR & $\mathrm{DE}$ & IT & $\mathrm{BE}$ & $\mathrm{CV}$ & BA & $\mathrm{PH}$ & RU & US \\
\hline Latvia & 476 & 15 & 30 & .044 & LT & PL & $\mathrm{EE}$ & $\mathrm{DE}$ & GB & RU & BY & UA & GE & $\mathrm{KZ}$ \\
\hline Netherlands & 458 & 63 & 93 & .292 & $\mathrm{DE}$ & $\mathrm{BE}$ & PL & GB & ES & ID & SR & TR & MA & IR \\
\hline Norway & 295 & 43 & 62 & .294 & SE & DK & GB & $\mathrm{DE}$ & $\mathrm{PL}$ & US & IQ & PK & $\mathrm{BA}$ & IR \\
\hline Poland & 125 & 16 & 28 & -.014 & $\mathrm{DE}$ & FR & LT & AT & IT & RU & BY & UA & US & $\mathrm{AM}$ \\
\hline Portugal & 209 & 25 & 39 & .122 & ES & FR & $\mathrm{RO}$ & $\mathrm{BG}$ & & $\mathrm{BR}$ & $\mathrm{CV}$ & $\mathrm{MZ}$ & GW & UA \\
\hline Romania & 27 & 10 & 14 & -.067 & AT & GR & $\mathrm{HU}$ & $\mathrm{BG}$ & & MD & RU & UA & $\mathrm{AL}$ & HR \\
\hline Sweden & 625 & 70 & 121 & .308 & FI & $\mathrm{DE}$ & NO & DK & PL & BA & IR & IQ & TR & LB \\
\hline Slovenia & 377 & 18 & 30 & -.033 & AT & $\mathrm{DE}$ & IT & FR & PL & HR & BA & MK & US & $\mathrm{AU}$ \\
\hline Slovak Republic & 196 & 14 & 27 & .043 & $\mathrm{CZ}$ & $\mathrm{HU}$ & PL & RO & AT & UA & RU & US & $\mathrm{AU}$ & $\mathrm{NG}$ \\
\hline
\end{tabular}

${ }^{1}$ Number of immigrants in country sample; ${ }^{2}$ No. Of origin countries; ${ }^{3}$ No. Of immigrant communities;

${ }^{4}$ Average GEM difference between country and immigrant community; ${ }^{5}$ ISO country codes 


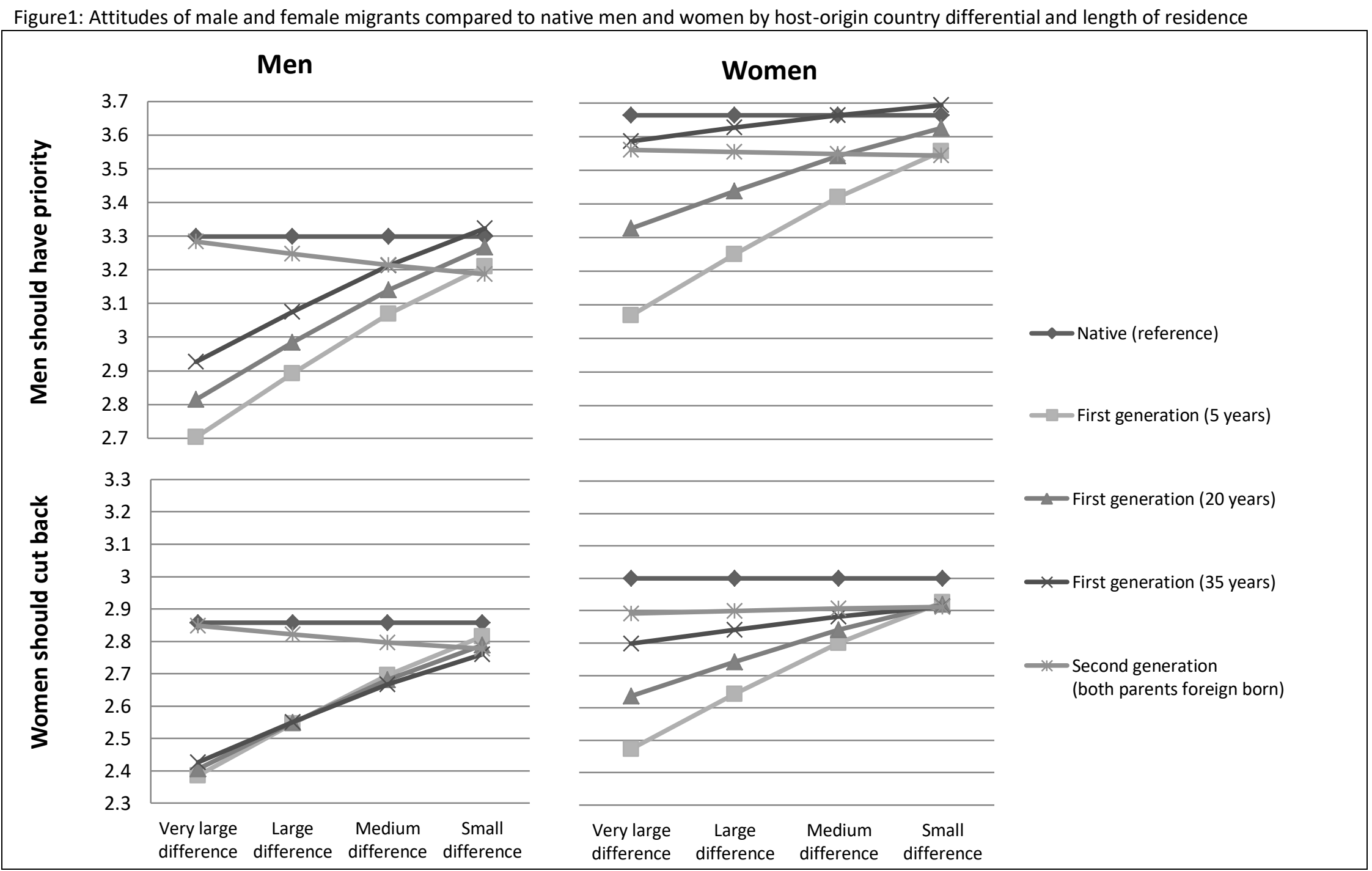


